\title{
Sete novas espécies de bruquídeos do gênero Amblycerus Thunberg (Coleoptera, Bruchidae) ${ }^{1}$
}

\author{
Cibele S. Ribeiro-Costa ${ }^{2}$
}

\begin{abstract}
Seven new species of bruchids of the genus Amblycerus Thunberg (Coleoptera, Bruchidae). New species are described and illustrated: Amblycerus isabelae sp.n., A. bidentatus sp.n., A. denticulatus sp.n., A. similaris sp.n., A. similis sp.n., $A$. isocalcaratus sp.n. and $A$. luciae sp.n.. These species are recorded from Brazil and one of them, A. bidentatus sp.n., also recorded from Paraguai.

KEY WORDS. Coleoptera, Bruchidae, Amblycerus, taxonomy
\end{abstract}

Amblycerus Thunberg, 1815 distribui-se nas regiões Neártica e Neotropical e é o segundo maior gênero de Bruchidae em número de espécies. KINGSOLVER (1990) citou 102 espécies descritas e comentou que provavelmente devam existir ainda 150 a serem descritas. As espécies dos Estados Unidos e México foram estudadas por ROMERO et al. (1996), resultando no estabelecimento de 15 grupos de espécies. As espécies brasileiras vem sendo descritas e nesta contribuição acrescenta-se mais sete espécies ao gênero.

A metodologia utilizada segue àquela descrita em RiBEIRO-CosTA (1997).

O material examinado pertence às seguintes instituições: Carnegie Museum of Natural History, Pittsburgh (CMNH); Coleção de Entomologia Pe. Jesus S. Moure, Curitiba (DZUP); Instituto Miguel Lillo, Tucumán (IMLA); Museu de Zoologia, Universidade de São Paulo, São Paulo (MZSP); Museu Nacional do Rio de Janeiro, Rio de Janeiro (MNRJ); Museu Paraense Emílio Goeldi, Belém (MPEG); Museum G.Frey, Tutzing (MGFT); e National Museum of Natural History, Washington (USNM).

As sete espécies aqui descritas compartilham os seguintes caracteres:

Fronte levemente achatada. Olhos grandes, protraídos lateralmente (Fig. 1); lobo pós-ocular estreito (Figs 3, 4, 18). Antena (Figs 2, 48) serreada a partir do quarto artículo; último artículo subelíptico. Pronoto com sulco cervical presente nos 1/3 laterais e com sulco em parte do bordo posterior; carena lateral (Figs 4, 18) longa, não bifurcada anteriormente. Élitros com estrias fortemente impressas. Metasterno lateralmente sem pontos grossos. Coxa posterior nos 2/3 laterais com pontos grossos distribuídos mais centralmente (Figs 6, 20). Porção distal da margem ventral do fêmur posterior, não denteada. Tíbia posterior com espinhos coronais aproximadamente do mesmo tamanho (Fig. 7); face ventral convexa com linha de pontos e cerdas grossas inconspícuas nas margens.

1) Contribuição número 1058 do Departamento de Zoologia, Universidade Federal do Paraná.

2) Departamento de Zoologia, Universidade Federal do Paraná. Caixa Postal 19020, 81531-990 Curitiba, Paraná, Brasil. bolsista do CNPq.

E-mail: stra@bio.ufp.br 


\section{Amblycerus isabelae sp.n.}

Figs 1-13

Dimensões: comprimento $3,92-4,33 \mathrm{~mm}(\overline{\mathrm{x}}=4,17 \mathrm{~mm} ; \mathrm{n}=3)$; largura 2,50 $2,67 \mathrm{~mm}(\overline{\mathrm{x}}=2,58 \mathrm{~mm} ; \mathrm{n}=3)$.

Tegumento. Coloração geral testácea. Élitros com manchas irregulares escurecidas, mais concentradas na $1 / 2$ apical (Fig. 8).

Pilosidade. Cabeça, apêndices e região mediano-ventral com pilosidade flava distribuída uniformemente. Pronoto flavo, lateralmente com duas manchas fulvas freqüentemente em forma de "M" (Fig. 9). Escutelo fulvo (Fig. 8). Élitros (Fig. 8) flavos entremeados com pêlos fulvos e marrons; os pêlos fulvos em geral, distribuídos como segue: terceira interestria com uma faixa subasal e dois pequenos grumos ou uma curta faixa apical, quarta interestria com uma pequena faixa subasal, quinta interestria com duas ou três faixas na metade basal, sexta interestria com uma faixa na metade basal, sétima interestria com uma faixa na região subasal e uma subapical, nona interestria com uma faixa na região subasal e dois ou três grumos apicais. Pigídio flavo com uma pequena faixa curva ou dois grumos de cada lado e um apical, marrons (Fig. 11). Algumas vezes metepisterno e coxa posterior flavos com manchas marrons. Abdome lateralmente com manchas arredondadas, fulvas no primeiro e último urosternitos; outros esternos freqüentemente com manchas flavas.

Olhos grossamente facetados (quatro omatídios). Índice ocular 5,7 (Fig. 1); sinus ocular $1 / 4,2$ vezes o diâmetro do olho em vista lateral; lobo pós-ocular $1 / 20$ vezes o maior comprimento do olho em vista lateral (Fig. 3). Oitavo, nono e décimo artículos antenais tão longos quanto largos (Fig. 2). Pronoto trapezoidal com margens laterais levemente arqueadas em vista dorsal; sem pontos grossos no disco. Processo prosternal delgado, levemente ou não expandido além das coxas anteriores. Escutelo cerca de 1,9 vezes mais longo que largo, com ápice unidenteado (Fig. 10). Élitros convexos ao longo da sutura elitral, arredondados apicalmente. Metepisterno com pontos grossos adensados (Fig. 5) ou ausentes; eixo transversal do sulco metepisternal divergindo dorsalmente, eixo longitudinal aproximadamente a metade ou menos que a metade do comprimento do metepisterno (Fig. 5), sem área estriada transversalmente. Coxas anteriores nitidamente acima das médias em vista lateral (Fig. 4). Fêmur posterior 2,6 vezes mais longo que largo (Fig. 7); porção distal da face ventral lisa. Tíbia posterior (Fig. 7) com esporão lateral 1,3 vezes o comprimento do mediano, o primeiro artículo tarsal posterior 2,4 vezes o comprimento do esporão lateral e 1,6 vezes do esporão mediano. Pigídio do macho e da fêmea em forte declive em vista lateral e arredondado apicalmente. Quinto urosternito suavemente emarginado no macho e truncado na fêmea.

Terminália do macho (Figs 12,13). Oitavo tergito arredondado apicalmente. Lobo médio (Fig. 12) com o comprimento 4,4 vezes a sua maior largura na região basal; valva ventral (Fig. 12-VV) moderadamente longa, com margens laterais côncavas, ápice afilado; valva dorsal (Fig. 12-VD) subtriangular com margens laterais retas, ápice levemente acuminado. Região basal do saco interno (Fig. 12-RB) com um par de escleritos médios (Fig. 12-EM) pequenos com protuberâncias arredondadas na base. Região mediana do saco interno com um par de escleritos 

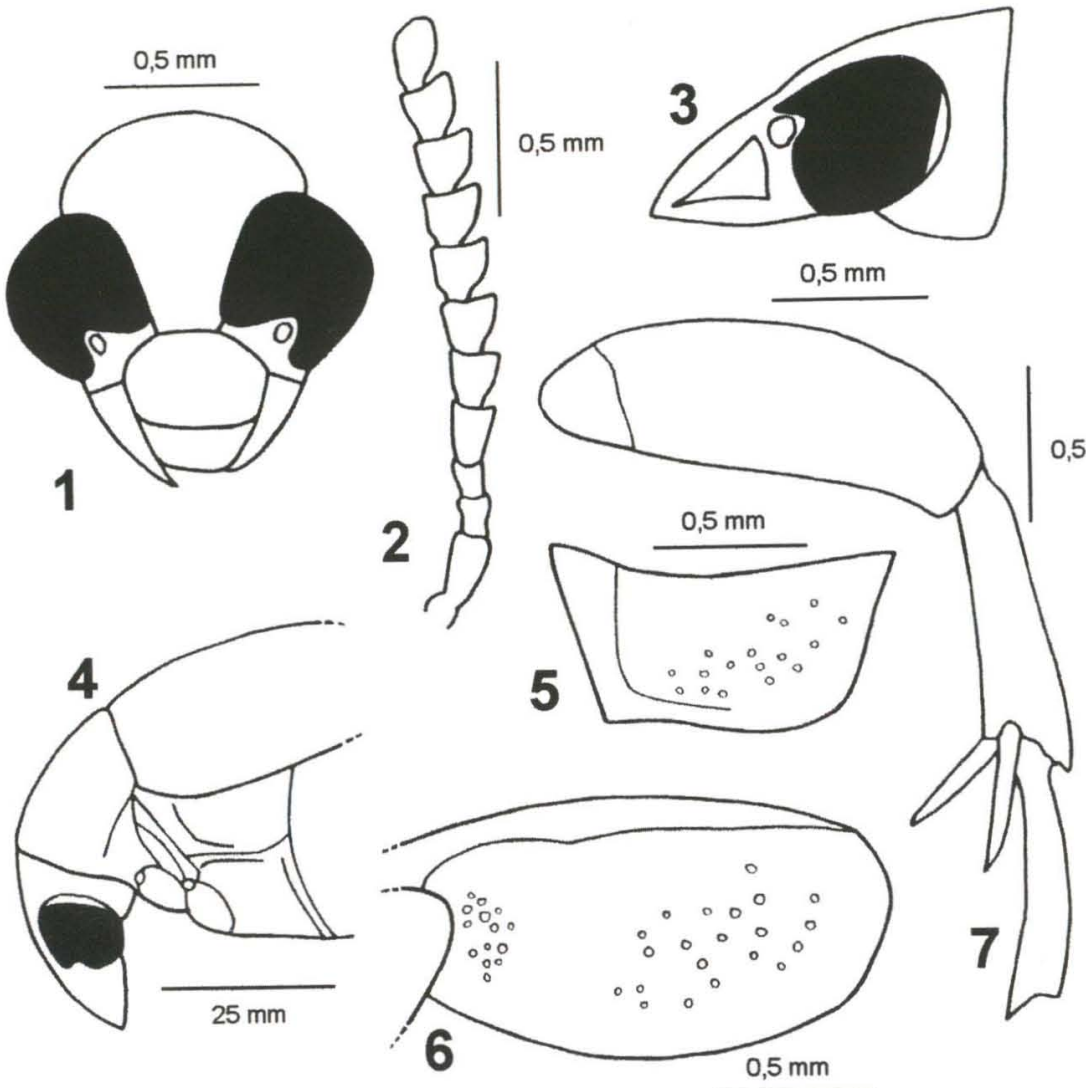

Figs 1-7. Amblycerus isabelae sp.n. (1) Cabeça, vista frontal; (2) antena; (3) cabeça, vista lateral; (4) cabeça e tórax em vista lateral; (5) metepisterno; (6) coxa posterior; (7) trocânter, fêmur, tíbia e primeiro artículo tarsal da perna posterior.

laminares (Fig. 12-EL), moderadamente sinuosos, serreados na margem mediana, os dentes aproximados e com longos espinhos na base e mais curtos no terço apical; um esclerito ímpar (Fig. 12-EI) em forma de "U" invertido, a metade do comprimento dos laminares e serreado na margem subasal. Na região apical do saco interno (Fig. 12-RA) um esclerito com hastes longas gradualmente convergentes e distalmente separadas (Fig. 12-EA). Região basal e mediana do saco interno com vários espinhos, dentículos presentes na região apical. Tégmen com emarginação aguda entre os alargados lobos laterais (Fig. 13).

Discussão taxonômica. Esta espécie é proximamente relacionada à Amblycerus paulonotatus (Pic, 1906) não só com relação ao padrão de coloração no dorso e forma do escutelo como também pela disposição e forma geral dos escleritos do saco interno do macho. Amblycerus isabelae sp.n. diferencia-se pelo esclerito ímpar da região mediana do saco interno que é aproximadamente do mesmo tamanho que os laminares enquanto em $A$. paulonotatus atinge aproximadamente a metade do tamanho dos laminares. 

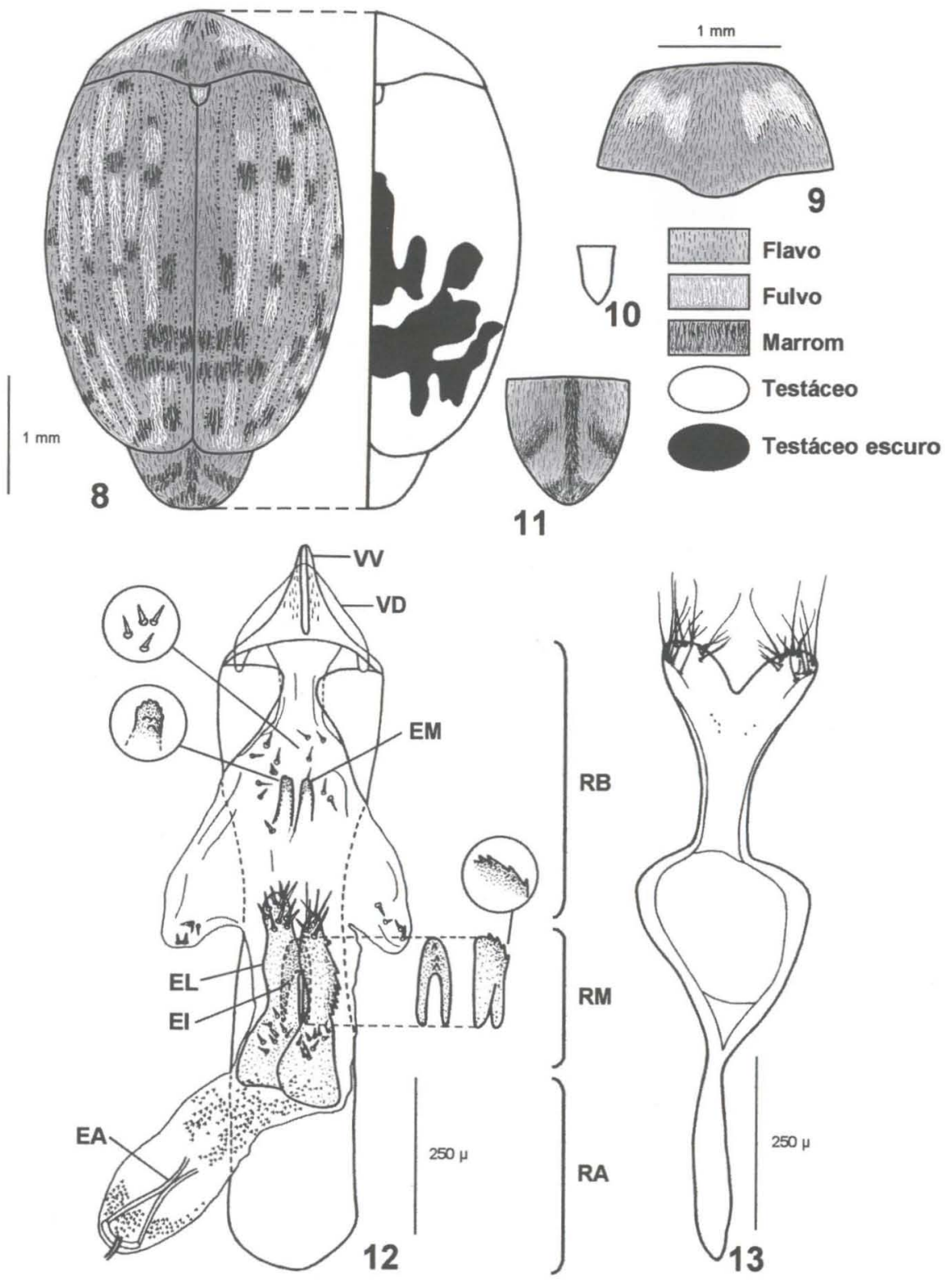

Figs 8-13. Amblycerus isabelae sp.n.. (8) Padrão de coloração do tegumento (círculo) e pilosidade (retângulo) no dorso; (9) pronoto; (10) escutelo; (11) pigídio. (12-13) Terminália do macho: (12) lobo médio; (13) tégmen. (RB) região basal do saco interno, (RM) região mediana do saco interno, (RA) região apical do saco interno, (VD) valva dorsal, (W) valva ventral, (EM) esclerito médio, (EL) esclerito laminar, (EI) esclerito impar, (EA) esclerito apical. 
Holótipo macho. BrasiL, Mato Grosso: Cáceres, XII.56, Alvarenga col. Três parátipos também do Mato Grosso, Chapada dos Guimarães, dois coletados por J. \& B. Bechyné, com as datas 4.II.61 e 19.I.1961 e um com a etiqueta BRASIL, [Mato Grosso]: Chapada [dos Guimarães], [H.H. Smith col.], nov., Acc. No 2966. Holótipo depositado no MGFT e os parátipos no MPEG, CMNH e DZUP.

Etimologia. Dedico o nome da espécie à minha filha que muito amo.

\section{Amblycerus bidentatus sp.n.}

Figs 14-23

Dimensões. Comprimento $3,50-5,00 \mathrm{~mm}(\overline{\mathrm{x}}=4,08 \mathrm{~mm} ; \mathrm{n}=3)$; largura 2,00 $2,92 \mathrm{~mm}(\overline{\mathrm{x}}=2,33 \mathrm{~mm} ; \mathrm{n}=3)$.

Tegumento. Coloração geral testácea (Fig. 14).

Pilosidade. Cabeça, apêndices e região mediano-ventral do tórax e abdome com pilosidade flava distribuída uniformemente. Pronoto (Fig. 15) flavo, lateralmente com uma mancha grande irregular, fulva; pilosidade marrom em pequenos grumos esparsos. Escutelo flavo (Fig. 14). Élitros (Fig. 14) fulvos com pêlos flavos distribuídos em linhas junto às bordas das interestrias; pilosidade marrom em pequenos grumos esparsos. Metepisterno, coxa posterior e abdome lateralmente com pêlos flavos e marrons; no abdome os marrons algumas vezes em grumos arredondados. Pigídio (Fig. 17) com pêlos flavos, fulvos e marrons; algumas vezes os fulvos adensados em linha vertical mediana.

Olhos grossamente facetados (quatro omatídios). Índice ocular 3,5; sinus ocular $1 / 3,6$ vezes o diâmetro do olho em vista lateral; lobo pós-ocular $1 / 20$ vezes o maior comprimento do olho em vista lateral. Oitavo, nono e décimo artículos antenais 1,3 vezes mais longos que largos. Pronoto trapezoidal com margens laterais levemente arqueadas em vista dorsal; sem pontos grossos no disco. Processo prosternal largo, levemente expandido além das coxas anteriores. Escutelo com comprimento quase o dobro de sua largura e ápice tridenteado (Fig. 16). Élitros convexos ao longo da sutura elitral, arredondados ou subtruncados apicalmente. Metepisterno com pontos grossos esparsos (Fig. 19) ou ausentes; eixo transversal do sulco metepisternal divergindo dorsalmente, eixo longitudinal aproximadamente a metade ou além da metade do comprimento do metepisterno (Fig. 19), sem área estriada transversalmente. Coxas anteriores aparentemente no mesmo nível que as médias em vista lateral (Fig. 18). Fêmur posterior 2,5 vezes mais longo que largo; porção distal da face ventral lisa. Tíbia posterior (Fig. 21) com esporão lateral 1,9 vezes o comprimento do mediano, o primeiro artículo tarsal posterior 1,5 mais longo que o esporão lateral e 2,7 vezes o comprimento do mediano. Pigídio do macho em forte declive em vista lateral e arredondado apicalmente. Quinto urosternito suavemente emarginado ou não. Fêmea não conhecida.

Terminália do macho (Figs 22, 23). Oitavo tergito truncado apicalmente. Lobo médio (Fig. 22) com o comprimento 4,1 vezes a sua maior largura na região basal; valva ventral curta com margens laterais côncavas, ápice afilado; valva dorsal subovalada ou subtriangular com margens laterais moderadamente convexas ou retas, ápice levemente acuminado ou arredondado. Região mediana do saco interno 

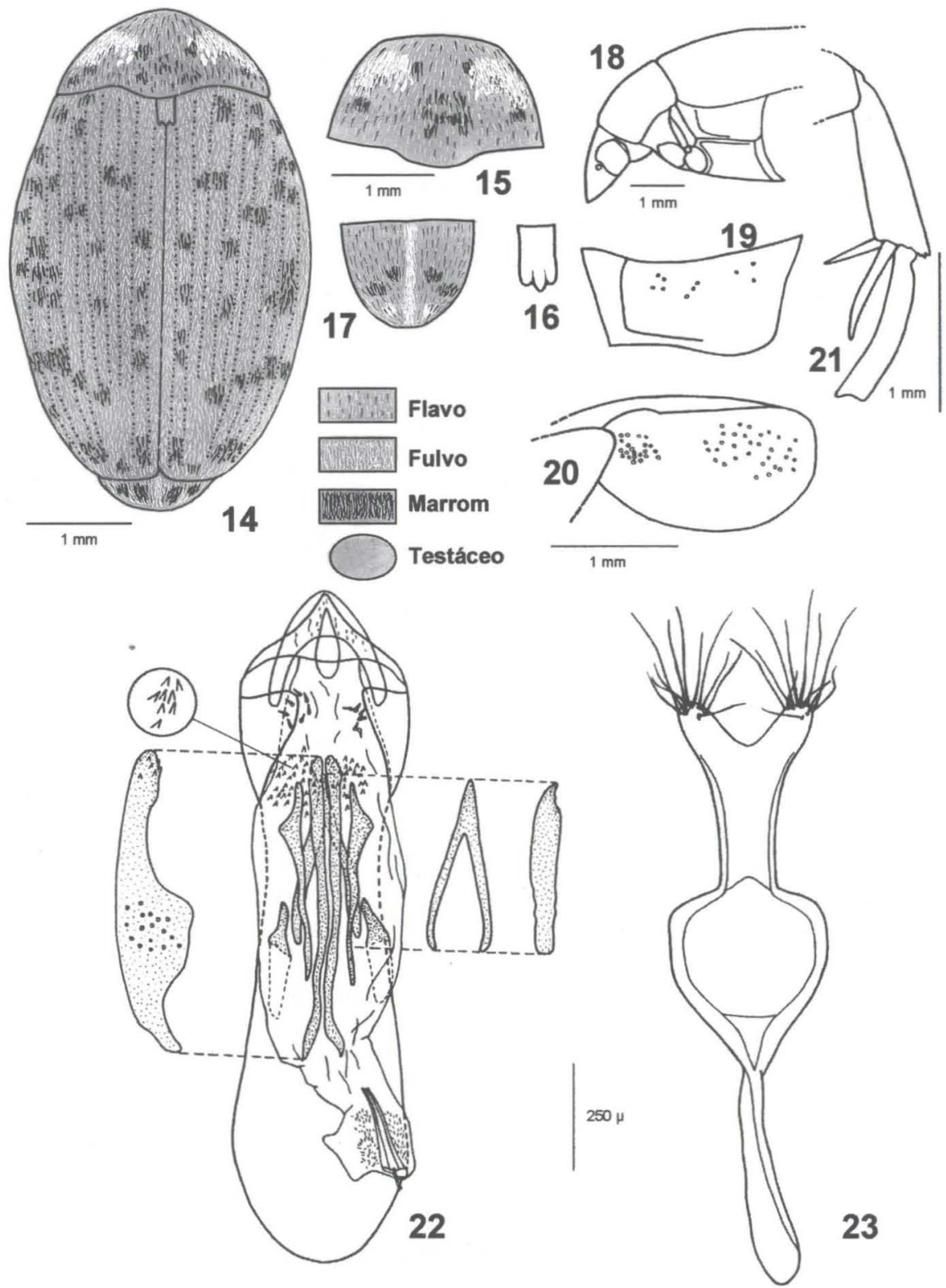

Figs 14-23. Amblycerus bidentatus sp.n.. (14) Padrão de coloração do tegumento (círculo) e pilosidade (retângulo) no dorso; (15) pronoto; (16) escutelo; (17) pigidio; (18) cabeça e tórax em vista lateral; (19) metepisterno; (20) coxa posterior; (21) tíbia e primeiro artículo tarsal posterior. (22-23) Terminália do macho: (22) lobo médio; (23) tégmen. 
com um par de escleritos laminares moderadamente sinuosos, com dentículos subasais; um esclerito em forma de forquilha cerca de 0,6 vezes o comprimento dos laminares com hastes levemente encurvadas e moderadamente separadas; um par de escleritos delgados, paralelos aos laminares; um par de dentes levemente encurvados próximos às hastes apicais do esclerito em forma de forquilha. Na região apical do saco interno um esclerito com hastes longas, gradualmente convergentes. Região basal do saco interno com vários espinhos e na região mediana área com dentículos adensados. Tégmen (Fig. 23) com forte emarginação arredondada entre os delgados lobos laterais.

Discussão taxonômica. Amblycerus bidentatus sp.n. é afim de A. denticulatus sp.n., A. perfectus (Sharp, 1885) e A. imperfectus Kingsolver, 1980 principalmente por compartilharem o mesmo padrão de coloração da pilosidade no dorso, escutelo tridenteado e dentes em torno dos escleritos da região mediana do saco interno do macho. Com relação aos outros caracteres de terminália do macho, a afinidade entre as citadas espécies não é muito evidente, pois o número e disposição dos escleritos do saco interno são diferentes. ROMERO et al. (1996) estabeleceram o grupo perfectus apenas com A. perfectus. Acredita-se que as espécies acima citadas devam também pertencer a este agrupamento.

Amblycerus bidentatus sp.n. pode ser diagnosticada pela forma, tamanho e número dos escleritos do saco interno do macho.

Holótipo macho. BrasiL, Minas Gerais: Araxá, 6.XI.965, C.T. Elias col. Três parátipos com as etiquetas BRASIL, Goiás: Dianópolis, 16-22.I.1962, J. Bechyné col.; Brasil, Goiás: Corumbá de Goiás, 3.I-3.II.1962, J. Bechyné col.; PARAGUAI: Depto. S. Pedro: Corumbé, 1.II-8.III.66, Golbach col.. Holótipo depositado no DZUP, dois parátipos no MZSP e um parátipo no IMLA.

Etimologia. O nome da espécie refere-se a presença de dois dentes no conjunto de escleritos medianos do saco interno do macho.

\section{Amblycerus denticulatus, sp.n.}

Figs $24-28$

Amblycerus denticulatus sp.n. é semelhante a A.bidentatus sp.n. exceto pelos seguintes caracteres:

Dimensões: comprimento $3,58-3,92 \mathrm{~mm}(\overline{\mathrm{x}}=3,75 \mathrm{~mm} ; \mathrm{n}=2)$; largura 2,08 $2,25(\bar{x}=2,17 \mathrm{~mm} ; \mathrm{n}=2)$.

Tegumento. Algumas vezes cabeça e região lateral e ventral do tórax, testáceo mais escurecido.

Pilosidade. Élitros algumas vezes com grumos irregulares de pilosidade fulva entremeados com grumos flavos e alguns marrons formando um padrão suavemente manchado.

Olhos grossamente facetados (7 omatídios). Índice ocular 3,61; sinus ocular $1 / 4,0$ vezes o diâmetro do olho em vista lateral; lobo pós-ocular $1 / 8,3$ vezes o maior comprimento do olho em vista lateral. Oitavo, nono e décimo artículos antenais tão longos quanto largos. Escutelo 1,7 vezes tão longo quanto largo, com ápice 

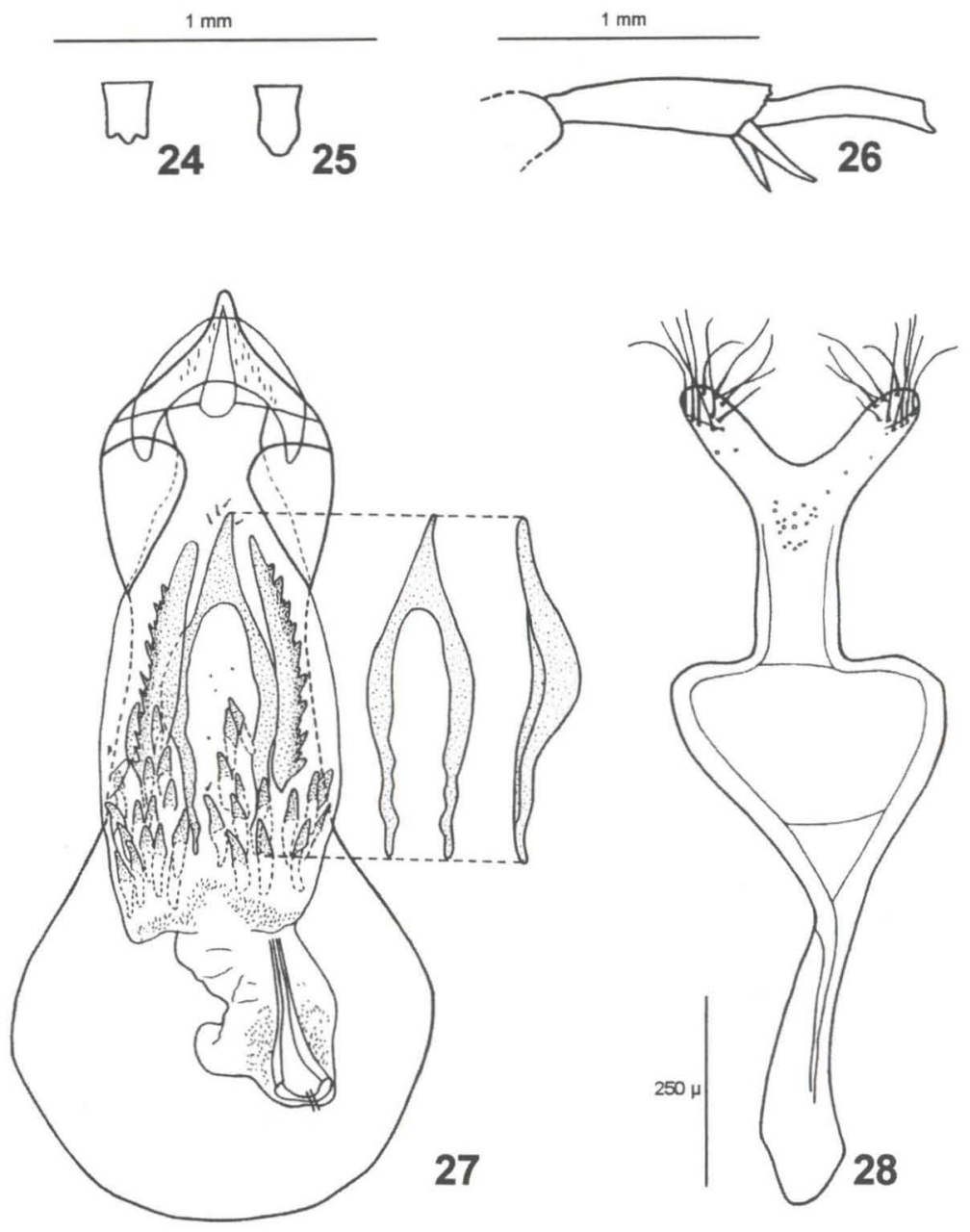

Figs 24-28. Amblycerus denticulatus sp.n.. (24-25) Escutelo; (26) tíbia e primeiro artículo tarsal posterior. (27-28) Terminália do macho: (27) lobo médio; (28) tégmen.

tridenteado (Fig. 24) ou subtriangular (Fig. 25). Metepisterno sem pontos grossos. Tíbia posterior (Fig. 26) com esporão lateral 1,5 vezes o comprimento do mediano, o primeiro artículo tarsal posterior 1,9 vezes o comprimento do esporão lateral e 2,4 vezes o do esporão mediano. Quinto urosternito suavemente emarginado ou levemente agudo no macho. Fêmea não conhecida.

Terminália do macho (Figs 27,28). Oitavo tergito arredondado apicalmente. Lobo médio (Fig. 27) com valva ventral moderadamente longa. Região mediana do saco interno com um par de escleritos laminares retos ou levemente arqueados e com um lado serreado, os dentes desiguais e aproximados; um esclerito em forma 
de forquilha 1,3 vezes o comprimento dos laminares; vários dentes (cerca de 32) distribuídos próximos ao ápice do conjunto de escleritos medianos. Região mediana do saco interno com vários espinhos dispersos.

Discussão taxonômica. Os caracteres diagnósticos de A. denticulatus sp.n. são aqueles relacionados ao número, forma e tamanho dos escleritos do saco interno da terminália do macho. Outros comentários em A. bidentatus sp.n.

Holótipo macho. Brasil, Goiás: Dianópolis, 16-22.I.1962, J. Bechyné col. Um parátipo do BRASIL, Minas Gerais: Paraopeba, sem data, E. P. Heringer col.. Holótipo depositado no MZSP e o parátipo no USNM.

Etimologia. O nome da espécie refere-se a presença de muitos dentes próximos ao ápice do conjunto de escleritos medianos do saco interno do macho.

\section{Amblycerus similaris sp.n.}

Figs 29-35

Dimensões. Comprimento 3,83-4,58mm ( $\overline{\mathrm{x}}=4,25 \mathrm{~mm} ; \mathrm{n}=3)$; largura 2,33$2,83 \mathrm{~mm}(\overline{\mathrm{x}}=2,58 \mathrm{~mm} ; \mathrm{n}=3)$.

Tegumento. Coloração geral testácea (Fig. 29).

Pilosidade. Cabeça, apêndices e região mediano-ventral do tórax e abdome com pilosidade flava distribuída uniformemente. Pronoto (Fig. 30) flavo, lateralmente com três ou quatro pequenos grumos de pêlos fulvos; algumas vezes área alongada fulva medianamente. Escutelo fulvo (Fig. 29). Élitros (Fig. 29) a partir da terceira interestria, alternadamente, com pilosidade fulva em grumos, alguns ligeiramente alongados entremeados com grumos marrons; pêlos fulvos distribuídos como segue: terceira interestria com 6-7 grumos, quinta com 5-6 grumos, sétima com 6-7 grumos e nona com 7 grumos. Restante das interestrias flavas com grumos marrons entremeados (mais nítidos nas duas primeiras interestrias) (Fig. 29). Pigídio (Fig. 31) com pilosidade flava levemente mais adensada na região basal e em linha vertical mediana; no centro da linha média pêlos marrons entremeados com flavos formando duas áreas ovaladas; áreas látero-medianas com dois grumos fulvos. Metepisterno, coxa posterior e lateralmente no abdome com pêlos flavos e marrons em padrão suavemente manchado; algumas vezes pêlos flavos adensados em áreas arredondadas laterais nos urosternitos.

Olhos grossamente facetados (sete omatídios). Índice ocular 5,6; sinus ocular $1 / 4$ do diâmetro do olho em vista lateral; lobo pós-ocular $1 / 20$ vezes o maior comprimento do olho em vista lateral. Oitavo, nono e décimo artículos antenais tão longos quanto largos. Pronoto semicircular com margens laterais moderadamente arqueadas em vista dorsal; pontos grossos no disco ausentes. Processo prosternal delgado, levemente expandido além das coxas anteriores. Escutelo com comprimento o dobro de sua largura e ápice bidenteado (Fig. 32). Élitros convexos ao longo da sutura elitral, arredondados apicalmente. Metepisterno com pontos grossos adensados ou ausentes; eixo transversal do sulco metepisternal divergindo dorsalmente, eixo longitudinal longo, além da metade do comprimento do metepisterno, sem área estriada transversalmente. Coxas anteriores nitidamente acima das coxas médias em vista lateral. Fêmur posterior 2,4 vezes mais longo que largo; porção 

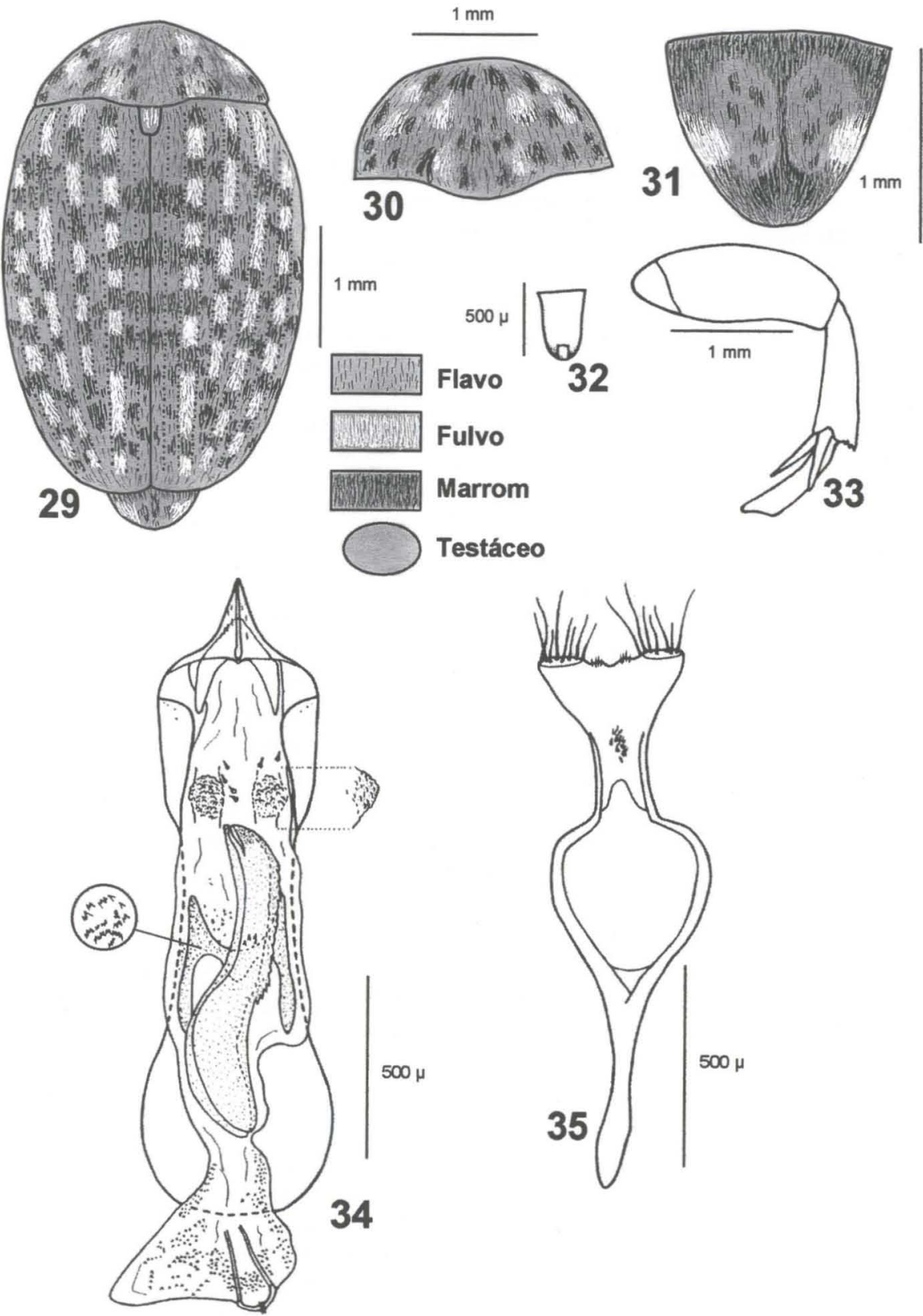

Figs 29-35. Amblycerus similaris sp.n.. (29) Padrão de coloração do tegumento (círculo) e pilosidade (retângulo) no dorso; (30) pronoto; (31) pigídio; (32) escutelo; (33) trocânter, fêmur, tíbia e primeiro artículo tarsal da perna posterior. (34-35) Terminália do macho: (34) lobo médio; (35) tégmen. 
distal da face ventral lisa. Tíbia posterior (Fig. 33) com esporão lateral 1,2 vezes o comprimento do mediano, o primeiro artículo tarsal posterior 1,6 vezes o comprimento do esporão lateral e 1,9 vezes o do esporão mediano. Pigídio do macho em forte declive e da fêmea em declive moderado em vista lateral e arredondado apicalmente. Quinto urosternito suavemente emarginado no macho e truncado na fềmea.

Terminália do macho (Figs 34,35). Oitavo tergito arredondado apicalmente. Lobo médio (Fig. 34) com o comprimento 4,3 vezes a sua maior largura na região basal; valva ventral moderadamente longa com margens laterais côncavas, ápice afilado; valva dorsal triangular. Região basal do saco interno com um par de escleritos posteriores ovalados, convexos e com pequenas protuberâncias arredondadas. Região mediana do saco interno com um par de escleritos laminares moderadamente sinuosos, serreados na margem lateral até a metade de seu comprimento, os dentes aproximados; um esclerito em forma de "M" 0,4 vezes o comprimento dos laminares. Na região apical do saco interno um esclerito com hastes longas paralelas, não convergentes. Região basal do saco interno com vários espinhos; região mediana com dentículos, estes simples ou micro-serreados. Tégmen (Fig. 35) com suave emarginação entre os delgados lobos laterais.

Discussão taxonômica. Esta espécie, A. similis sp.n. e Amblycerus geminatus (Sharp, 1885) são proximamente relacionadas quando observados os caracteres externos como padrão de pilosidade nos élitros e pigídio, forma do escutelo e comprimento dos esporões da tíbia posterior. Apenas o fêmur posterior mostra-se diferente, mais alargado em A. geminatus e A. similaris sp.n. (Fig. 33) e geralmente mais delgado em $A$. similis sp.n. (Fig. 38). Os caracteres relacionados aos escleritos do saco interno do macho não confirmam a estreita afinidade entre as citadas espécies, contribuindo de forma significativa para a diferenciação das mesmas.

Holótipo macho. Brasil, Mato Grosso do Sul: Campo Grande, 9.X.1961; F.M. Oliveira col. Dois parátipos, um com os mesmos dados do holótipo e outro com a etiqueta BRAsIL, Mato Grosso: Chapada dos Guimarães, 20.I.1961; J. \& B. Bechyné col.. Holótipo e um parátipo depositados no DZUP e o outro parátipo no MPEG.

Etimologia. O nome da espécie indica a grande semelhança em caracteres externos com $A$. similis sp.n.

\section{Amblycerus similis sp.n.}

Figs $36-40$

A descrição de $A$. similis sp.n. é semelhante a de $A$. similaris sp.n. exceto pelos seguintes caracteres:

Dimensões. Comprimento 3,25-4,00mm $(\bar{x}=3,75 \mathrm{~mm} ; \mathrm{n}=5)$; largura 1,92$2,33 \mathrm{~mm}(\overline{\mathrm{x}}=2,25 \mathrm{~mm} ; \mathrm{n}=5)$.

Pilosidade. Número de grumos fulvos nos élitros, distribuídos como segue: terceira interestria com 5-7 grumos, quinta interestria com dois ou quatro grumos, sétima interestria com dois ou cinco grumos e nona com três ou seis grumos; restante das interestrias com pêlos flavos e alguns marrons em raros grumos. Quando os 

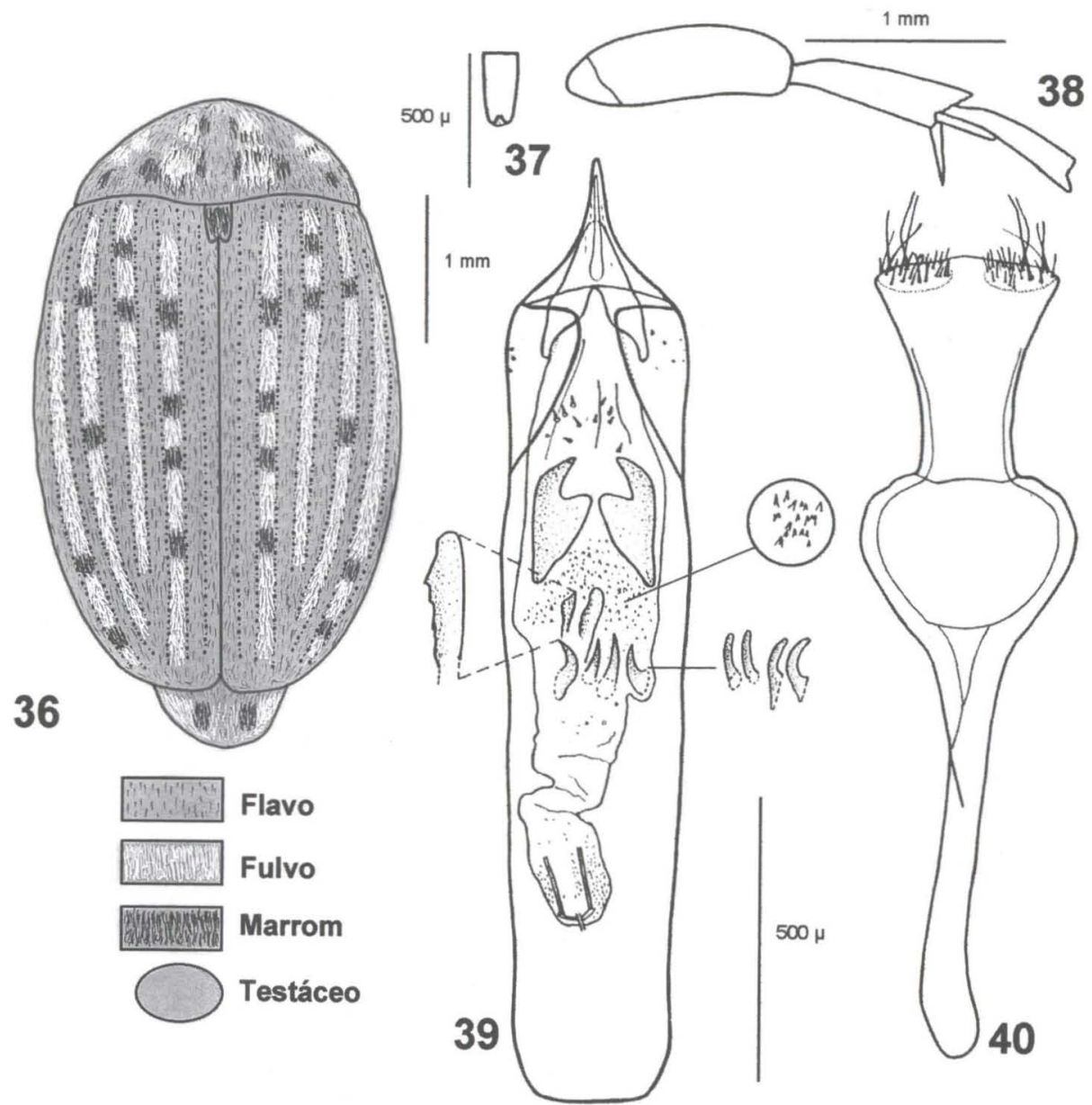

Figs 36-40. Amblycerus similis sp.n.. (36) Padrăo de coloração do tegumento (circulo) e pilosidade (retângulo) no dorso; (37) escutelo; (38) trocânter, fêmur, tíbia e primeiro artículo tarsal da perna posterior. (39-40) Terminália do macho: (39) lobo médio; (40) tégmen.

grumos de pêlos marrons a partir da terceira interestria, alternadamente, são em menor número, a pilosidade fulva, nestas áreas, quase forma distintas faixas longitudinais (Fig. 36).

Olhos grossamente facetados (sete omatídios). Índice ocular 4,3; lobo pósocular $1 / 8,3$ vezes o maior comprimento do olho em vista lateral. Disco do pronoto com pontos grossos de igual tamanho aos das laterais ou ausentes. Escutelo cerca de 2,6 vezes mais longo que largo, com ápice bidenteado (Fig. 37). Metepisterno com pontos grossos ausentes. Fêmur posterior (Fig. 38) cerca de 2,6 mais longo que largo. Tíbia posterior (Fig. 38) com o primeiro artículo tarsal posterior 2,4 vezes tão longo quanto o esporão lateral e o dobro do esporão mediano. Pigídio do macho em declive moderado e da fềmea em forte declive em vista lateral. 
Terminália do macho (Figs 39, 40). Lobo médio (Fig. 39) com o comprimento cerca de 5,5 vezes a sua maior largura na região basal; valva ventral longa; valva dorsal subtriangular, ápice arredondado. Região basal do saco interno com um par de escleritos posteriores em forma de garra apendiculada. Região mediana do saco interno com um par de escleritos laminares retos e com um lado serreado; dois dentes externos fortemente encurvados e dois mais internos retos ou distribuídos como na figura 39, próximo ao ápice dos laminares. Tégmen (Fig. 40) sem emarginação entre os lobos laterais, estes pouco definidos.

Discussão taxonômica. Em A. similaris sp.n.

Holótipo macho. Brasil, Goiás: Dianópolis, 11-14.I.1962, J. Bechyné col.. Cinco parátipos; quatro com a mesma etiqueta do holótipo, exceto um deles com a data de 16-22.1962, e outro com a etiqueta BRASIL, [Mato Grosso]: Chapada [dos Guimarães], oct., [H.H. Smith col.], Acc. No 2966. Holótipo e dois parátipos depositados no MZSP, dois no DZUP e um parátipo no CMNH.

Etimologia. O nome da espécie indica a grande semelhança em caracteres externos com A. similaris sp.n.

\section{Amblycerus isocalcaratus sp.n.}

Figs 41-47

Dimensões. Comprimento $3,67-4,17 \mathrm{~mm}(\overline{\mathrm{x}}=3,92 \mathrm{~mm} ; \mathrm{n}=2)$; largura 2,17$2,50 \mathrm{~mm}(\overline{\mathrm{x}}=2,33 \mathrm{~mm} ; \mathrm{n}=2)$.

Tegumento. Coloração geral testácea (Fig. 41). Pronoto e élitros com manchas irregulares dispersas testáceo escuras (Fig. 41).

Pilosidade. Cabeça, apêndices (exceto coxa posterior) e região mediano-ventral do tórax e abdome com pilosidade flava distribuída uniformemente. Pronoto com pêlos flavos e marrons formando um padrão suavemente manchado e, lateralmente com três grumos de pêlos fulvos dispostos em triângulo (Fig. 41). Escutelo fulvo (Fig. 41). Élitros semelhantes ao pronoto, com grumos fulvos distribuídos como segue: terceira interestria com cinco ou oito grumos, quinta com dois ou cinco grumos, sétima com cinco grumos e nona com três grumos na metade apical (Fig. 41). Pigídio (Fig. 44) com duas manchas marrons nas áreas ântero-laterais e na região submediana e uma na região apical, restante com pêlos fulvos claros levemente adensado em faixa mediana. Metepisterno, coxa posterior e abdome lateralmente com pilosidade flava e marrom formando um padrão levemente manchado. Pilosidade flava levemente adensada em grumo lateral no primeiro urosternito.

Olhos grossamente facetados (sete omatídios). Índice ocular 4,4 ; sinus ocular $1 / 5,9$ vezes o diâmetro do olho em vista lateral; lobo pós-ocular $1 / 20$ vezes o maior comprimento do olho em vista lateral. Oitavo, nono e décimo artículos antenais cerca de 0,9 vezes tão longos quanto largos. Pronoto trapezoidal com margens laterais levemente arqueadas em vista dorsal; pontos grossos no disco de tamanho igual aos grossos das laterais ou ausentes. Processo prosternal delgado, levemente expandido além das coxas anteriores. Escutelo com comprimento geralmente o dobro de sua largura e ápice tridenteado (Figs 42, 43). Élitros convexos ao longo da sutura elitral, arredondados apicalmente. Metepisterno sem pontos grossos; eixo 

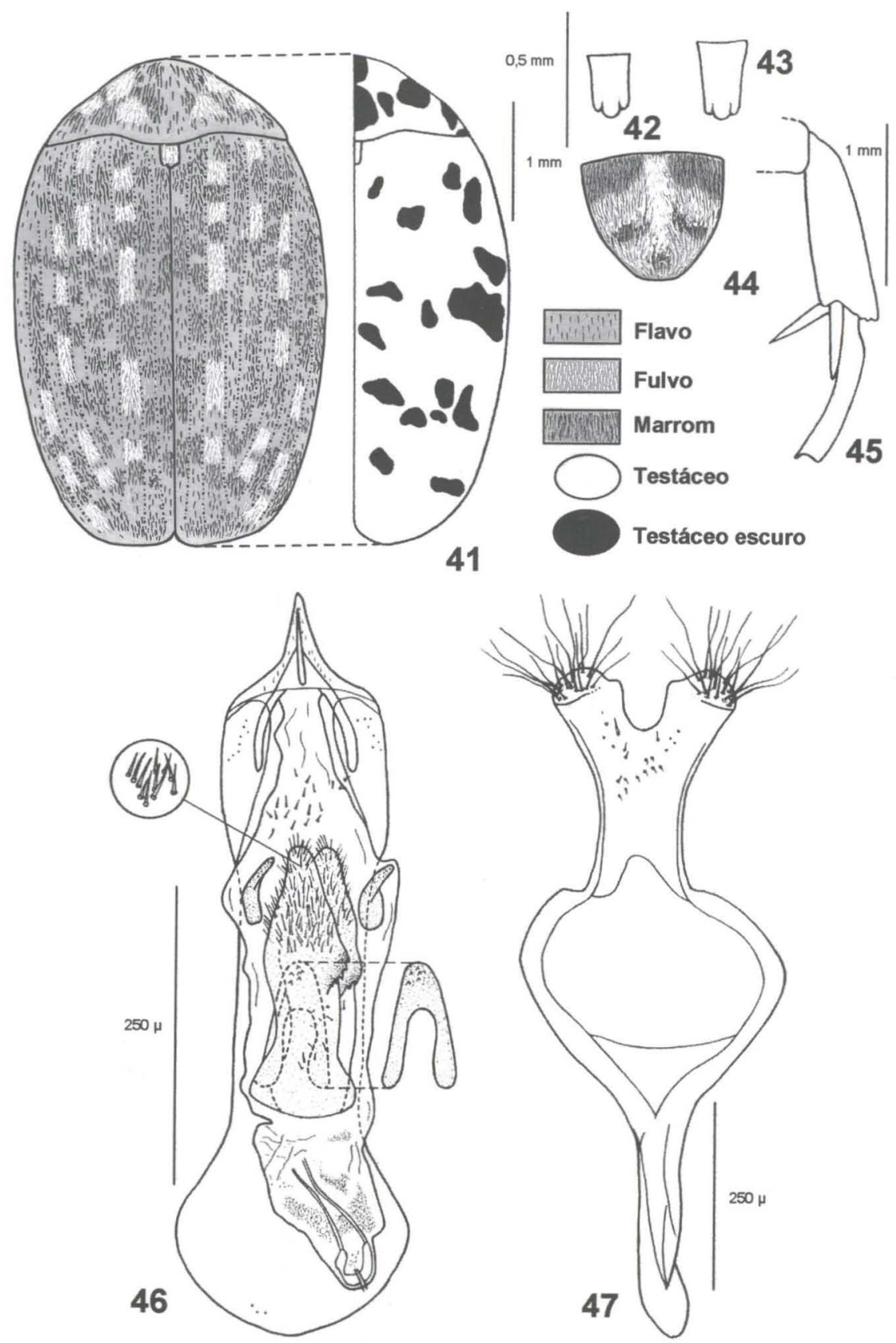

Figs 41-47. Amblycerus isocalcaratus sp.n.. (41) Padrão de coloração do tegumento (círculo) e pilosidade (retângulo) no dorso; (42-43) escutelo: (44) pigídio; (45) trocânter, fêmur, tíbia e primeiro artículo tarsal da perna posterior. (46-47) Terminália do macho: (46) Lobo médio; (47) tégmen. 
transversal do sulco metepisternal divergindo dorsalmente, eixo longitudinal aproximadamente a metade ou além da metade do comprimento do metepisterno, sem área estriada transversalmente. Coxas anteriores nitidamente acima das coxas médias em vista lateral. Fêmur posterior 2,5 mais longo que largo; porção distal da face ventral, lisa. Tíbia posterior (Fig. 45) com esporão lateral 1,1 vezes o comprimento do mediano, o primeiro artículo tarsal posterior 2,1 o comprimento do esporão lateral e 2,2 vezes o do esporão mediano. Pigídio do macho em forte declive e da fêmea em declive moderado; arredondado apicalmente. Quinto urosternito suavemente emarginado no macho e truncado na fềmea.

Terminália do macho (Figs 46, 47). Oitavo tergito arredondado apicalmente. Lobo médio (Fig. 46) com o comprimento cerca de 5,0 vezes a sua maior largura na região basal; valva ventral moderadamente longa com margens laterais côncavas, ápice afilado; valva dorsal triangular, ápice levemente acuminado. Região mediana do saco interno com um par de escleritos laminares levemente sinuosos, serreados na margem lateral da região mediana, os dentes aproximados e com muitos espinhos longos na região subasal e basal; um esclerito em forma de "U" invertido com pequenos dentes basais, a metade do comprimento dos laminares; um par de escleritos levemente encurvados próximos à região subasal dos laminares. Na região apical do saco interno um esclerito com hastes longas, gradualmente convergentes e separadas apicalmente. Na região basal e mediana do saco interno com vários espinhos. Tégmen (Fig. 47) com forte emarginação arredondada entre os lobos laterais delgados.

Discussão taxonômica. Esta espécie não se mostra proximamente relacionada a outras do gênero e pode ser facilmente diagnosticada pelo padrão de coloração no dorso, além da forma e disposição dos escleritos do saco interno da terminália do macho.

Holótipo macho. Brasil, [Mato Grosso]: Chapada [dos Guimarães], nov., [H.H. Smith col.], Acc. № 2966. Dois parátipos com os mesmos dados do holótipo. Holótipo e um parátipo depositados no CMNH e um parátipo no DZUP.

Etimologia. O nome da espécie refere-se aos esporões subiguais da tíbia posterior.

\section{Amblycerus luciae sp.n.}

Figs $48-53$

Dimensões. Comprimento $6,58-7,33 \mathrm{~mm}(\overline{\mathrm{x}}=7,00 \mathrm{~mm} ; \mathrm{n}=4)$; largura 4,17$4,42 \mathrm{~mm}(\overline{\mathrm{x}}=4,33 \mathrm{~mm} ; \mathrm{n}=4)$.

Tegumento. Coloração geral rufa. Cabeça, apêndices e região lateral e ventral do tórax, testáceos.

Pilosidade. Corpo com pilosidade flava distribuída uniformemente. Região ventral do tórax e coxa posterior geralmente com pêlos mais claros.

Olhos grossamente facetados (quatro omatídios). Índice ocular 3,8; sinus ocular $1 / 3,1$ vezes o diâmetro do olho em vista lateral; lobo pós-ocular $1 / 5,9$ vezes o maior comprimento do olho em vista lateral. Oitavo, nono e décimo artículos antenais cerca de 1,6 vezes mais longos que largos (Fig. 48). Pronoto trapezoidal 

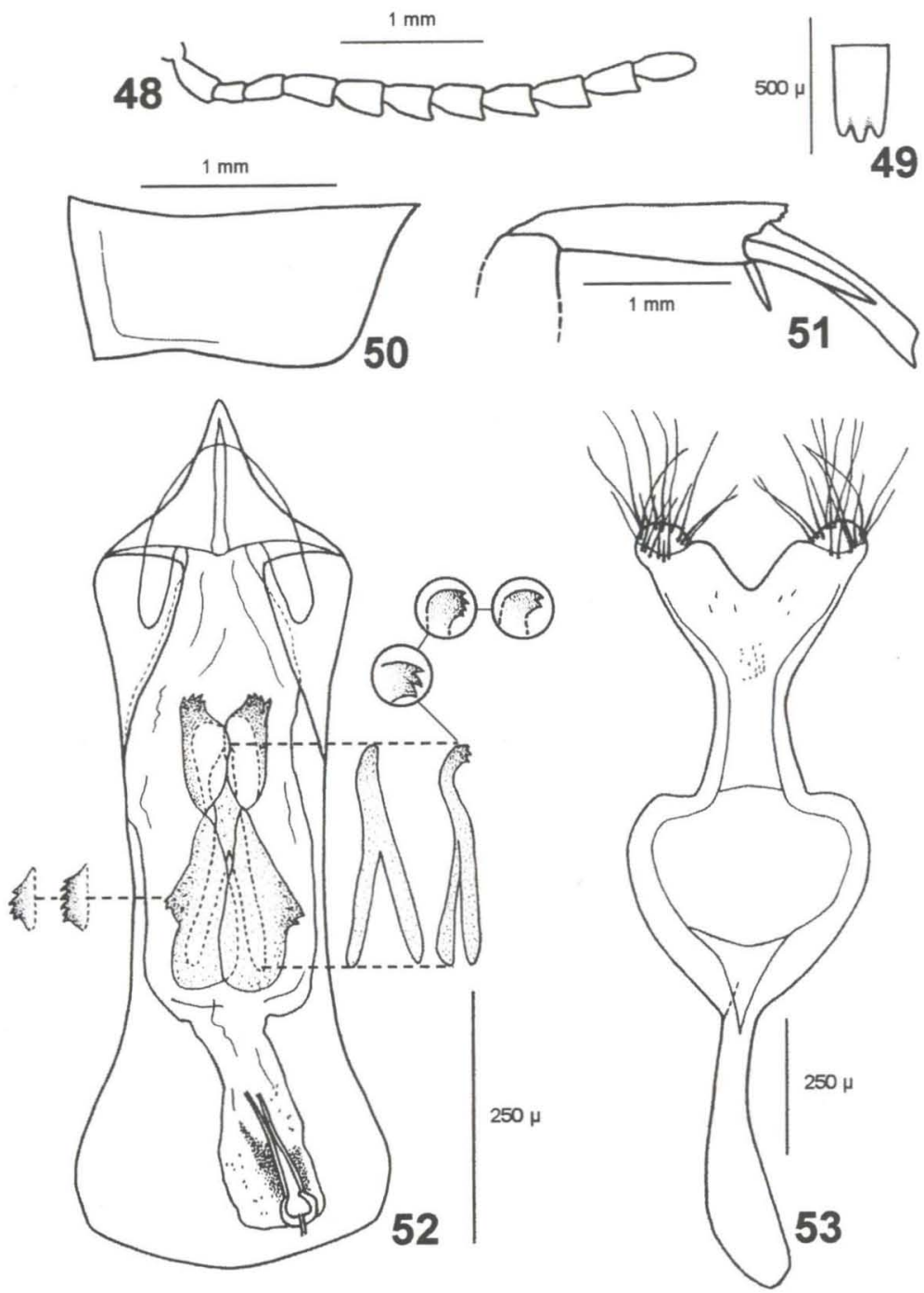

Figs 48-53. Amblycerus luciae sp.n.. (48) Antena; (49) escutelo; (50) metepisterno; (51) tíbia e primeiro artículo tarsal da perna posterior. (52-53) Terminália do macho: (52) lobo médio; (53) tégmen.

com margens laterais levemente arqueadas em vista dorsal, sem pontos grossos no disco. Processo prosternal largo, levemente expandido além das coxas anteriores. Escutelo com comprimento o dobro de sua largura e ápice tridenteado (Fig. 49). Élitros planos ao longo da sutura elitral, subtruncados apicalmente. Metepisterno sem pontos grossos; eixo transversal do sulco metepisternal paralelo dorsalmente, eixo longitudinal aproximadamente a metade do comprimento do metepisterno (Fig. 
50), sem área estriada transversalmente. Coxas anteriores aparentemente no mesmo nível que as médias em vista lateral. Fêmur posterior 2,8 vezes mais longo que largo; porção distal da face ventral, lisa. Tíbia posterior (Fig. 51) com esporão lateral 2,9 vezes o comprimento do mediano, o primeiro artículo tarsal posterior 1,3 vezes tão longo quanto o esporão lateral e 3,8 vezes o esporão mediano. Pigídio do macho em forte declive em vista lateral; arredondado ou subtruncado apicalmente. Quinto urosternito suavemente emarginado no macho. Fêmea não conhecida.

Terminália do macho (Figs 52, 53). Oitavo tergito arredondado apicalmente. Lobo médio (Fig. 52) com o comprimento de 3,5 vezes a sua maior largura na região basal; valva ventral moderadamente longa com margens laterais côncavas, ápice afilado; valva dorsal subovalada. Região basal do saco interno com um par de escleritos posteriores subovalados, côncavos e com quatro dentes curtos basais. Região mediana do saco interno com um par de escleritos laminares retos com dois, quatro ou seis dentes na margem da região mediana (Fig. 52), os dentes aproximados; um esclerito em forma de forquilha 1,2 vezes tão longo quanto os laminares, com hastes moderadamente separadas e ápice bi, tri ou quadridenteado (Fig. 52). $\mathrm{Na}$ região apical do saco interno um esclerito com hastes longas gradualmente convergentes e separadas apicalmente. Região basal e mediana do saco interno com alguns espinhos. Tégmen (Fig. 53) com emarginação aguda entre os alargados lobos laterais.

Discussão taxonômica. Amblycerus luciae sp.n. é intimamente relacionada à Amblycerus pterocarpae Kingsolver, 1980, compartilhando com esta muitos caracteres externos e internos da terminália do macho. A diferença mais marcante entre ambas encontra-se no tamanho do esclerito ímpar situado na região mediana do saco interno do macho. Amblycerus luciae sp.n. deve pertencer ao grupo "pterocarpae" estabelecido por Romero et al. (1996) para abrigar a espécie $A$. pterocarpae.

Holótipo macho. BrasiL, Amazonas: sem localidade, 1941, Constanço col.. Três parátipos com os mesmos dados do holótipo. Holótipo e um parátipo depositados no MNRJ e dois parátipos no DZUP.

Etimologia. Dedico o nome da espécie à minha grande amiga Lúcia Massutti de Almeida.

AGRADECIMENTOS. Ao Dr. John M. Kingsolver pelo acesso às notas sobre os tipos de Amblycerus, a Dra. Danúncia Urban pela revisão do manuscrito e ao Pe. Jesus S. Moure pelas sugestões na elaboração dos nomes das espécies.

\section{REFERÊNCIAS BIBLIOGRÁFICAS}

KingSOLVER, J.M. 1980. Eighteen new species of Bruchidae, principally from Costa Rica, with host records and distributional notes (Insecta: Coleoptera). Proc. Biol. Soc. Wash. 93 (1): 229-283.

1990. New world Bruchidae. Past, present, future, p.121-129. In: K. FusII; A.M.R. Gatehouse; C.D. Johson; R. Mitchel \& T. TOShiDa (Eds). Bruchids and Legumes: Economics, Ecology and Coevolution. Netherlands, Klewer Academic Publishers, 407p. 
PIC, M. 1906. Nouveaux Coléotères d'Europe, Asie, Afrique et Amérique. Échange 22: $1-5$.

Ribeiro-Costa, C.S. 1997. Descrições de oito novas espécies de Amblycerus (Thunberg, 1815) (Coleoptera, Bruchidae). Revta bras. Zool. 14 (3): 629-648 [1998].

ROMERO, J.; C.D. JOHNSON \& J.M. KingSOLVER. 1996. Revision of the genus Amblycerus of the United States and Mexico (Coleoptera: Bruchidae: Amblycerinae). U.S. Dep. Agric., Tec. Bull. (1845): 1-166.

Sharp, D. 1885. Bruchidae, p.437-504. In: Godman, F.D. \& O. SAlvin (Eds). Biologia Centrali-Americana, Insecta, Coleoptera 5.

Recebido em 14.V.1998; aceito em 16.VIII.1999 